\title{
The dinosaur that lost its head: $A$ contribution to a framework for using Learning Analytics in Learning Design
}

René Boyer Christiansen, Professionshøjskolen Absalon

Karsten Gynther, Professionshøjskolen Absalon

Rasmus Jørnø, Professionshøjskolen Absalon

\section{Abstract}

This paper presents an approach to the meaningful use of learning analytics as a tool for teachers to improve the robustness of their learning designs. The approach is based on examining how participants act within a Massive Open Online Course (MOOC) format through learning analytics. We show that a teacher/ designer can gain knowledge about his or her intended, implemented and attained learning design; about how MOOC participants act in response to these and about how students are able to develop 'study efficiency' when participating in a MOOC. The learning analytics approach makes it possible to follow certain MOOC students and their study behaviour (e.g. the participants who pass the MOOC by earning enough achievement badges) and to examine the role of the moderator in MOOCs, showing that scaffolding plays a central role in studying and learning processes in an educational format such as a MOOC.

Key words: MOOCs, Massive Open Online Courses, data-saturated, learning analytics, learning design, educational design research, LMS. 


\section{The link between Learning Design and Learning Analytics}

The use of digital data in education began some 30 years ago (Ross, 1990), and in the subsequent era of blended learning formats, digital and analogue went hand in hand. It was not until very recently that we became able to speak of the digital paths of learning in a learning environment in which all study activity is traceable via digital footprints. This can take place, for example, when learners enter a digital learning environment, such as a Massive Open Online Course (MOOC) (Hestbech \& Nortvig, 2016). This should not lead to yet another fruitless debate about qualitative educational research (e.g. classroom observations and analyses, interviews, video and so forth) versus quantitative (e.g. counting the movements, statements, behaviours in class, questionnaires, and so on) but rather, as Brophy (1995) suggests, to a 'shift in focus from methods to questions' (p. 11). The specific question framing our research in this article is the following:

\section{How can Learning Analytics support the professional teacher in his or her work with learning designs?}

We use the educational format of the Massive, Open, Online Course (MOOC) as an example of a learning environment where learning analytics can be used as a tool for improving learning designs. When working with Learning Analytics and learning designs, other formats could be relevant, but we have chosen MOOCs because they are naturally data-saturated environments, and they are, in this sense, suitable for learning analytics analyses. The learning platform (Moodle) in which these MOOCs are constructed can provide the requisite amount and kind of data needed for a learning analytics study.

To situate our research question in the current literature, the following presents a brief overview of two fields and their connection.

The fields of Learning Design (LD) and Learning Analytics (LA) are both fairly new domains of research, but in the last few years, they have garnered increasing interest (Nortvig, 2016). According to the introduction to a special journal issue on the connections between LD and LA, the aim of combining these fields is "to improve learning effectiveness" (Leo, Rodriguez-Triana, Inventado and Mor, 2017, p. 3). The precise nature of this synergistic potential has, however, not been settled. In this article, our research interests align with recent attempts to integrate the two fields into a single framework (Bakharia et al., 2016; Leo et al., 2017; Holmes \& Reedy, 2017; Lockyer, Heathcote \& Dawson, 2013; Persico \& Pozzi, 2015; Rienties, Nguyen, Sergis \& Sampson, 2017; Wise, Vytasek, Hausknecht \& Zhao, 2016). We seek to examine and develop a framework for the use of LA as an integrated part of $L D$.

LD is not yet a well-defined research field. Tellingly, there is still a good deal of uncertainty surrounding the use of the term learning design' (Dalziel et al., 2016). We have chosen to follow the recommendations laid out in the Larnaca Declaration (Dalziel et al., 2016), which differentiates between the research field (LD), written in uppercase letters, and a specific learning design (ld), written in lowercase letters. According to Conole (2013), LD can be defined as '[a] methodology for enabling teachers/ designers to make more informed decisions in how they go about designing learning activities and interventions, which is pedagogically informed and makes effective use of appropriate resources and technologies' (p. 8).

Persico and Pozzi (2015) divide LD efforts into three major areas of focus that each contribute to the design, sharing and reuse of pedagogical practices. First, the work of creating representations or models of formalized learning requires the analysis of learning processes, insights into the design process and an acute understanding of the trade-offs between capturing complexity and communicating designs in an easy-to-use manner. There are two main trends: capturing designs in text and capturing them 
visually. A second area is the development of approaches to guide the decision-making process of designing. Many of the developed methodologies seek to find generic ways to steer both the novice and the adept designer towards better outcomes. Finally, there are specific tools that aim to support LD processes. The authors cite different uses for these tools, such as gathering repositories of inspirational cases, best practices or principles and supporting the design process as it unfolds (authoring and sharing tools). This article places itself decidedly within the second area, finding ways to utilize LA as a tool to inform the decision-making process. The ld conceptual map found in the Larnaca Declaration (Dalziel et al, 2016, p. 10), shown in Figure 1 below, provides a model overview of the process of creating learning experiences. The central upper box depicts the teaching cycle, in which the teacher works on his or her design iteratively in cycles of designing, engaging with students and reflecting on the design. The upper left-hand side shows the factors informing this process, while the upper right-hand side emphasizes that designs can be created at different levels of organization, from the overall design of a program down to separate learning activities. The teaching cycle results in the (green) design that embodies core concepts and is implemented via tools and resources. The bottom LA forms a part of the learner responses that provide feedback information on how the designs are working:

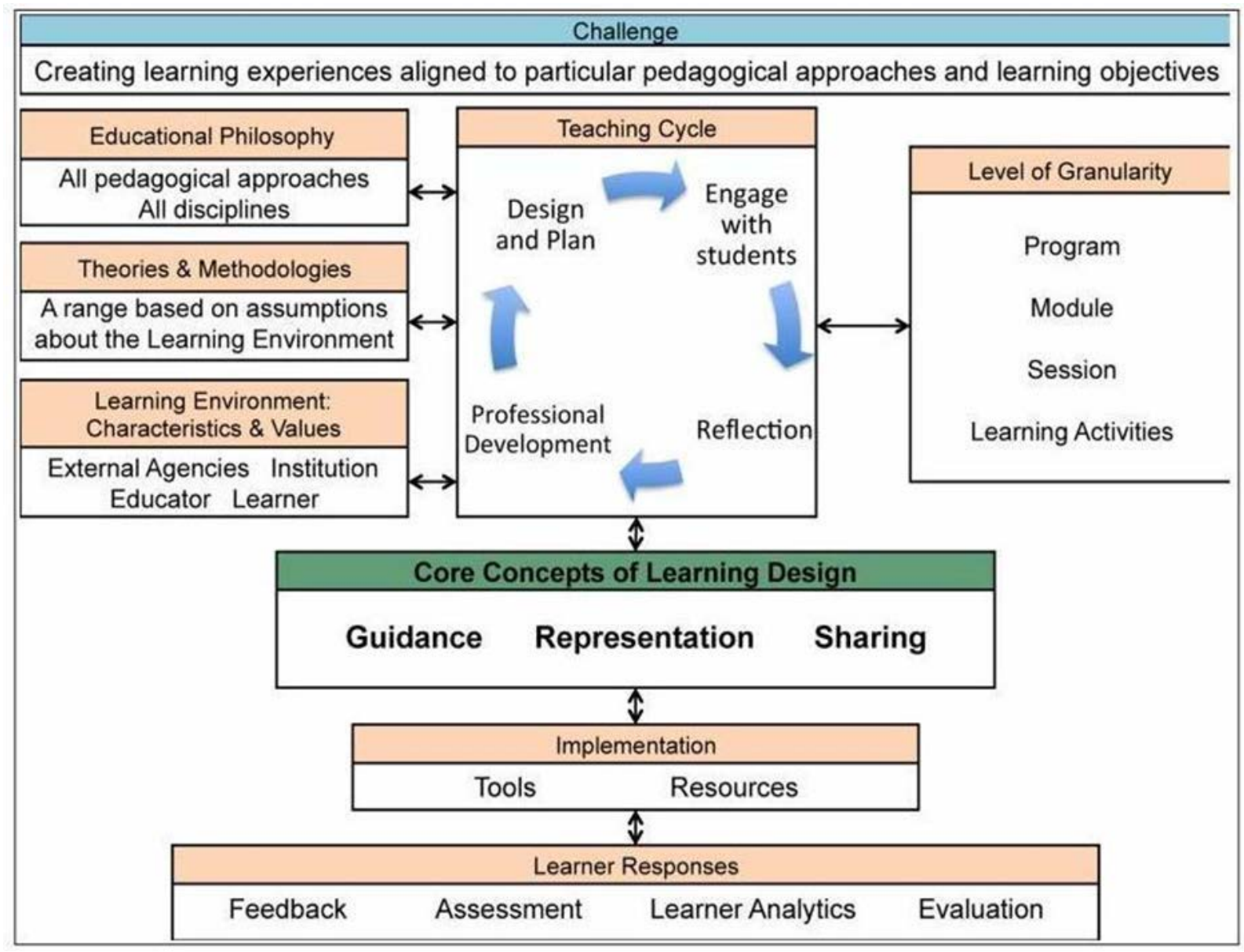

Figure 1: A Learning Design conceptual map.

Positioning LA as part of the information feedback into the design process makes sense from both an LA and LD perspective. However, it is important to mention that LA covers approaches that are outside the scope of LD. We follow the definition of LA given by the call to the first international conference on LA in 2011:

The measurement, collection, analysis and reporting of data about learners and their contexts, for purposes of understanding and optimizing learning and the environments in which it occurs' (LAK, 2011, np.). 
In parallel with the above terminology, we differentiate between 'Learning Analytics' (LA) in uppercase letters, referring to the research field, and learning analytics' (la) in lowercaseletters, a term for concrete analyses.

Like LD, the field of LA seeks to inform decision making (Nortvig 2016). But while LD focuses on helping teachers create pedagogically effective learning interventions (Conole, 2013), LA sees data as capable of informing decision making for teachers, students and mentors alike (Persico \& Pozzi, 2015). More to the point, there are many ways in which data can inform decision making for participants involved in learning processes; however, LD takes a decidedly teacher-centric perspective that reserves the role of the 'designer' for teachers (Wise et al., 2016). For that reason, we follow the recent convention that differentiates three types of designs:

The intended form of the interventions [intended design] refers to what it sets out to do. The implemented form of the intervention [implemented design] is that which is actually used in practice. The outputs and outcomes of an intervention constitutes its attained form [attained design]' (Mckenney \& Reeves, 2012, p. 139).

To the previous, one might add, 'from the point of view of a teacher/ designer'. It is, therefore, relevant to note that, regardless of what the data provided by learning analytics concerns (e.g. student test results, trace data or social network analysis), it is considered feedback on the teacher's design choices. If we relate this to Figure 1, we can see that LA is interjected into the 'teaching cycle' between 'engage with students' and 'reflection'. This view is predominant in the literature that connects LD and LA (Wise et al., 2016). Lockyer et al. (2013) speak of establishing a framework that helps teachers interpret the information that analytics provide' (p. 1439). Wise and others (2016) consider this task to be composed of two activities: 'Making sense of the information presented in the analytics and taking action based on this information' (p. 3). Sergis and Sampson (2017) propose, although under the headline 'teaching and learning analytics', that "insights generated by Learning Analytics methods and tools can become meaningfully translated for driving teachers' inquiry to improving their teaching practice, captured through Teaching Analytics methods and tools" (p. 25).

Persico and Pozzi (2015) suggest that LA takes educational data and 'distil[s] summaries or synopses to support decision making of the different actors involved at different stages in the learning process' ( $\mathrm{p}$. 234). This aligns with an emphasis in the LA literature on producing 'actionable insights' based on educational data (Clow, 2012; Gašević, Dawson \& Pardo, 2016; Liu, Bartimote-Aufflick, Pardo \& Bridgeman, 2017). We agree that many insights can be gleaned from educational data; however, as several authors have pointed out, data do not, in themselves, provide any guidance for action (Dyckhoff, Zielke, Bültmann, Chatti \& Schroeder, 2012; Nguyen, Rienties \& Toetenel, 2017; Sclater, Peasgood \& Mullan, 2016, Chatti, Dyckhoff, Schroeder \& Thüs, 2012). Therefore, we find it important to stress that it is only when contextualized that data turns into insights (Jørnø \& Gynther, 2018). The connection between LD and LA is, therefore, not simply one in which data are treated in the realm of LA and then turned over to designers in LD. Insights in LA are engendered by knowledge of the design decisions that created the data. Only in this light can data subsequently inform a redesign.

There are many types of data already established within LA. In the following pages, we limit ourselves to three: temporal analytics, comparative analytics and cohort analytics (Bakharia et al., 2016). Temporal analytics maps and analyses student trajectories over time. This approach visualizes participants' access and choices of resources and assignments, as well as their interactions with fellow students and moderators. Comparative analytics focuses on mapping and finding correlations between participants' demographic data, academic records and test scores in relation to their choices within an ld. Cohort analytics concerns grouping participants relative to their trajectories and results. One particular type of cohort analysis has attracted much attention: identifying groups at risk of attrition. The purpose is, of course, to intervene before it is too late to stop attrition. We have chosen to ignore such an analysis. The main reason for this is that our subject area is MOOCs. It is well established that 
it is possible to engage with a MOOC for a multitude of reasons and, in our case, opting to not complete a course cannot be meaningfully described as 'risk behaviour' (Bayne \& Ross, 2014; Onah, Sinclair \& Boyatt, 2014).

\section{Methodology and case}

The development of a framework that integrates LA into LD draws on methodology taken from designbased research and educational design research (Akker, Gravemeijer, McKenney \& Nieveen, 2006; Gynther, 2016; Gynther, Christensen \& Jørnø, 2013; Mckenney \& Reeves, 2012). We have, therefore, worked with an empirical case, working with teachers and designers/ developers in an iterative co-design process to develop ways in which learning analytics can contribute to the further development of a specific ld. In a subsequent generalisation phase, the goal of such a project would be to theoretically formulate grounded principles in the form of a framework that can support teachers in their work, integrating learning analytics into their learning design. The following case was chosen based on these criteria:

* The teaching and learning environments are, in themselves, data-saturated.

* The moderators and participants do not have to produce extraneous data to satisfy any learning analytics ambitions.

* The digital platform provides data that lend themselves to learning analytics analysis.

* The digital tools needed to generate and analyse the data are manageable.

Concurrently, we have attempted to choose a paradigmatic case that highlights more general characteristics' (Flyvbjerg, 2006, p. 232). From the point of view of the teacher/designer, these characteristics could be that:

* Teachers are not able, through ordinary professional tools, to see the variety in the 'implemented design'.

* The connection between LD and LA offers a transparent and professional potential for the teacher.

* The teachers are supported in an exemplary and transparent manner by the developed framework in the process of developing new learning designs.

The chosen case draws on data from a MOOC. As a learning environment, MOOCs are naturally datasaturated environments, and they are, in this sense, suitable for learning analytics analyses. The learning platform (Moodle) is able to provide the requisite amount and kind of data needed for a learning analytics study. Furthermore, it seems reasonable to assume that neither the designers of the intended design of the MOOC nor the moderators (teachers and facilitators) are able to establish an overview of the learning paths of the MOOC participants without the use of technology, as there are far too many data points. Therefore, a learning analytics approach is quite relevant. In this case, we have chosen to connect analyses of the intended MOOC design with analyses of the participants' learning paths.

A total of 244 persons participated in all or part of the MOOC during the nine weeks in the autumn of 2017 during which the MOOC was open. The figures used here have been produced using IBM SPSS software, which can easily handle the data generated from the Moodle platform. The data provide insight into the implemented design of the MOOC-i.e. what the participant actually did when he or she entered the MOOC to study. As mentioned, we have generated temporal analytics, cohort analytics (behavioural analytics) and comparative analytics. In this paper, we will not be addressing the attained design-i.e. the actual outcome of the participants studying in the MOOC. 
Upon entering the MOOC, all participants were asked to consent to the use of all data generated during the period in which the MOOC was open for students (autumn 2017) for research purposes. All data presented here come from consenting participants and have been anonymized. The data are stored at University College Absalon, following all national and international rules for data storage.

\section{Empirical findings}

\section{Learning design and learning analytics on various levels of granularity}

The above definition shows that LD covers a variety of granularity levels in education. As Dalziel et al. (2016) point out, the concept of 'granularity levels' is used in various ways in different educational domains at the program level, with a focus on curriculum design, module and session design and the design of learning analytics. In our analyses of a MOOC, we span several granularity levels to relate the intended design of the MOOC to the implemented design. For each analysis, we give recommendations related to future redesigns or efforts to make the intended design more robust. In the following, we first present the intended design of the MOOC, then follow results from the learning analytics data and finally, we argue what didactical designers can gain when working with learning analytics when constructing designs.

\section{The intended design of the MOOC on a module level}

On a module level (see the Larnaca figure 1 above) the MOOC described here has been categorized as a learning program concerning 'the open school'. The intended audience comprises professionals in and associated with primary schools in Denmark, particularly professionals working on concrete lesson plans for schools working with organizations in their surroundings. The MOOC consists of six modules. Three of these are common to all participants, while the participants were required to choose from one of the remaining three specialized modules, which deal with either cultural institutions, businesses or local associations. Therefore, the intended participant trajectory consisted of four modules in total. Each module was divided into sequences that led to an assignment. The completion of two assignments triggered a badge. A badge can be regarded as a digital "reward" that MOOC-participants can earn during their course work; and it doubles as a way of displaying progress and learning achievements to others. A certain number of badges can in some cases result in a diploma stating that the course has been completed successfully (Laso et al., 2013). Participants could collect two badges in each module. Collecting five or more badges in total earned the participant a diploma for the course.

This MOOC has been executed twice. The first time was in spring 2017 with 288 participants signing up, 183 of whom subsequently logged onto the platform. The second time was in fall 2017, with 280 signing up and 188 logging on at least once. This time, the MOOC was used as a teaching tool in a formal education setting for students of teaching and pedagogy. The data used in this article stems from round two. Concerning the cohort analysis, we can identify five different groups of participants: a) professionals working in the school system, b) professionals working outside the school system, c) teaching and pedagogy students at a Danish University College (UC), d) the teachers of these students, and e) the moderators who designed and moderated the MOOC.

\section{Learning Analytics}

Of the 188 logged-on participants, 141 were defined as 'active learners. Our criterion for a participant being categorized as an active learner was that the participant must have had a sum total of five or more 
clicks on any resource in the MOOC. The following analysis pertains only to the 141 active learners. The categories ' $d$ ' and ' $e$ ' have been filtered out. For groups 'a' and 'b', we followed recent research suggesting that the primary motivation for participation in a MOOC is interest in the subject and/or a desire to further one's career (Vivian, Falkner \& Falkner, 2014; Kellogg, Booth \& Oliver, 2014). For group 'c', the MOOC is part of a traditional course plan, and hence, the students' participation was heavily scaffolded by pedagogical/ld choices made by group ' $d$. .' Group ' $c$ ' was not intended to engage in all the modules of the MOOC, nor was it intended to seek a diploma. In our analysis, we were not able to differentiate between participants from groups ' $a$ ' and 'b' because no distinguishing information was required at registration. Thus, we ended up with two cohorts. The first consists of groups 'a' and 'b' (67 participants), and the second consists of group ' $c$ ' (74 participants).

\section{Diploma}

The main reason for the limited number of students who received a diploma is probably the very diverse motivations for and goals of participation. Figure 2 shows the distribution of badges on the $\mathrm{x}$-axis and the number of participants who scored that particular number of badges on the y-axis.

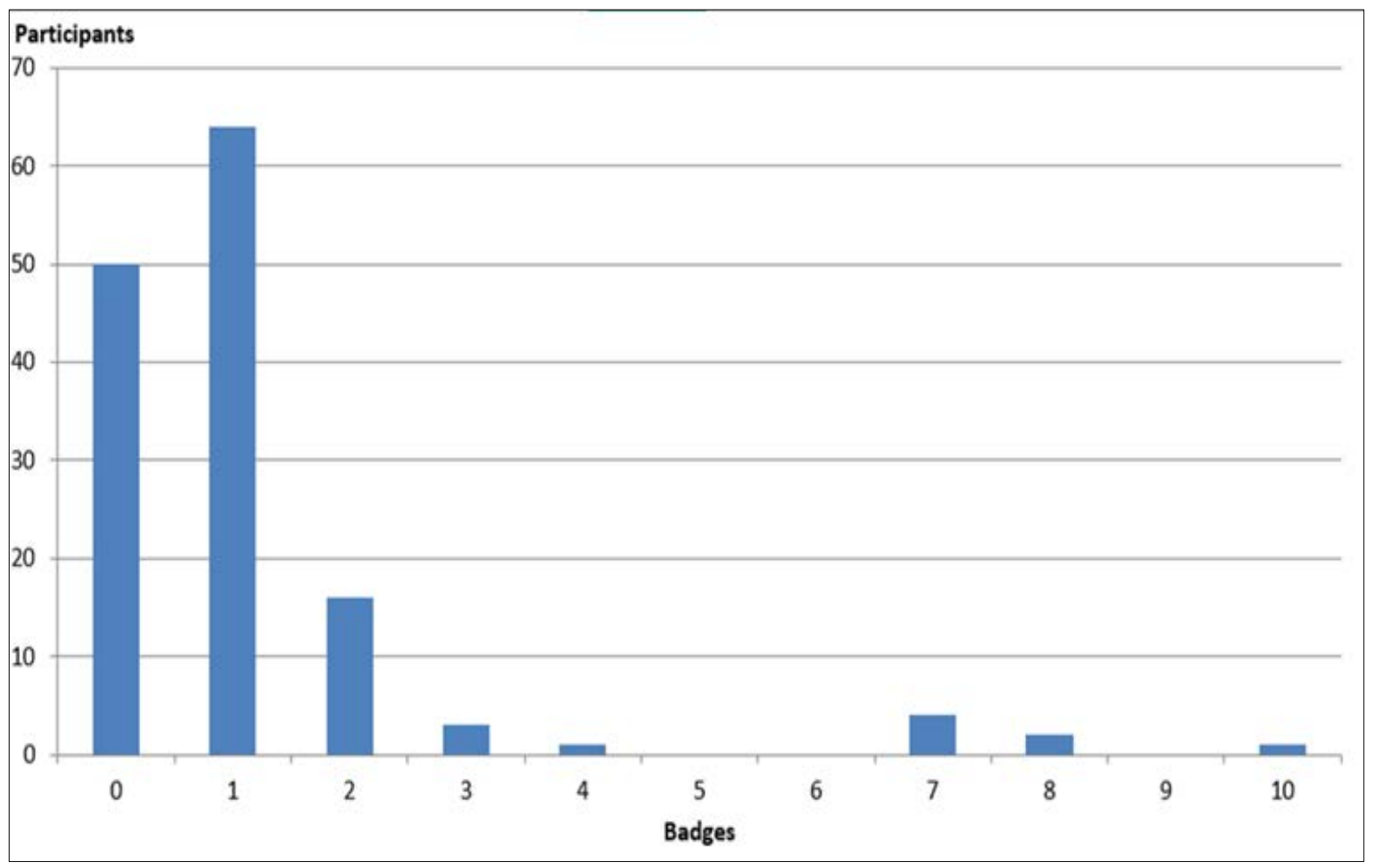

Figure 2: Number of badges per participant.

As is apparent, the figure displays a decidedly left-aligned dataset. Only seven out of 141 participants received five badges or more, thus qualifying for a diploma. The intended design for 'course completion' seems to have severely mutated (Hung, Lim \& Huang, 2010) in the implemented design in two ways: A large number of participants were nowhere near 'course completion' and seemed to be either unable to collect badges or uninterested in doing so. For a different, smaller group (7 participants), badges appeared to play an ancillary role in their motivation, as they all not only reached the required number of badges for a diploma but received significantly more badges than necessary. In the data, there is an isolated outlier participant who received 10 badges. This is a feat which, relative to the intended design, should not be possible. Out of the seven who received a diploma, there were no UC students (group ' $c$ ') which is unsurprising given their isolated use of the MOOC. We have chosen to take a closer look at the 
two above-mentioned mutations. Going forward, we will differentiate between the seven who received a diploma (group ' 2 '), the group of students who did not (group ' 1 ') and the remainder (group ' 0 ').

\section{Has the intended design been realized by the seven?}

At first glimpse, it would appear that group 2 (the seven) actualizes the intended design perfectly.

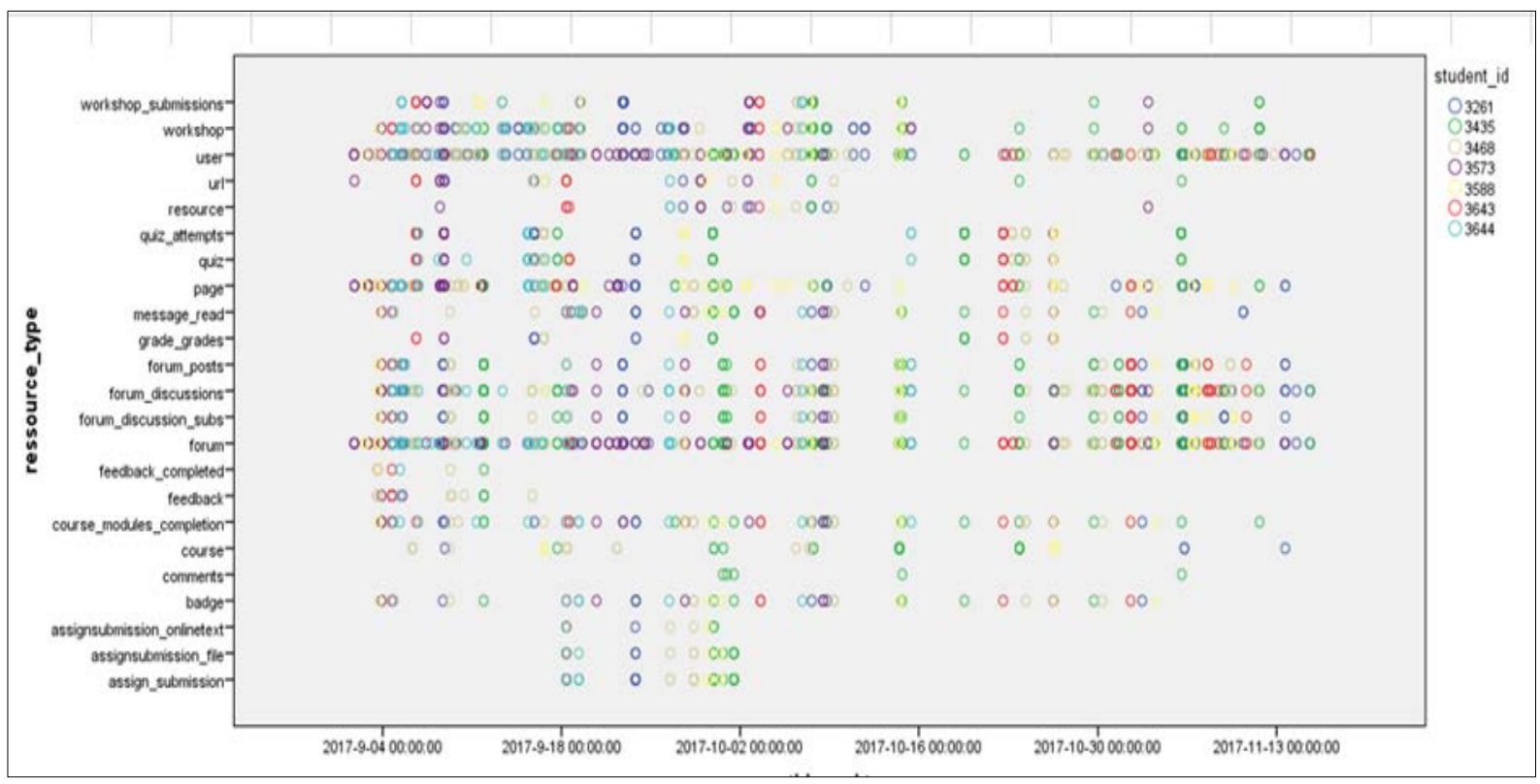

Figure 3: Group 2's logged activity with resources throughout the course period.

The above figure 3 visualizes group 2's (the seven) participant trajectories. Each participant has been assigned a colour code. Time is plotted along the horizontal line. The type of resource accessed at a given point in time is plotted along the vertical line. One might then identify patterns in the colour distribution. Vertical blocks of the same colour, for instance, could indicate a participant who has logged in to a wide range of resources over a single timeframe. An evenly distributed colour could indicate a very consistent participant, and so on.

The overall impression we get from Figure 3 is that group 2 (the seven) was active throughout the course period in all of the different module resources and activities. Achieving a diploma was, from an educational point of view, the traditional differentiator with which to observe the participants' behaviour. Given such a perspective, one might reach the conclusion that, for these participants, the implemented design matched the intended design 1:1. This conclusion would be difficult to corroborate or reject without further data. In a data-saturated environment, however, we are at an advantage in that we can follow the precise trajectories taken by the participants. By zooming in on the behaviour of group 2 , a different picture emerges—one that learning designers might find surprising.

\section{Study efficiency}

The MOOC is designed for a normal 37-hour weekly workload for each module. For the entire course of four modules, that adds up to 148 work hours or five ECTs. In the following, we closely examine group 2 's work activity to gauge how they structured their work. Was there a correlation between the intended workload and the actual workload for these seven students?

We can start by examining their footprints relative to their logins. 


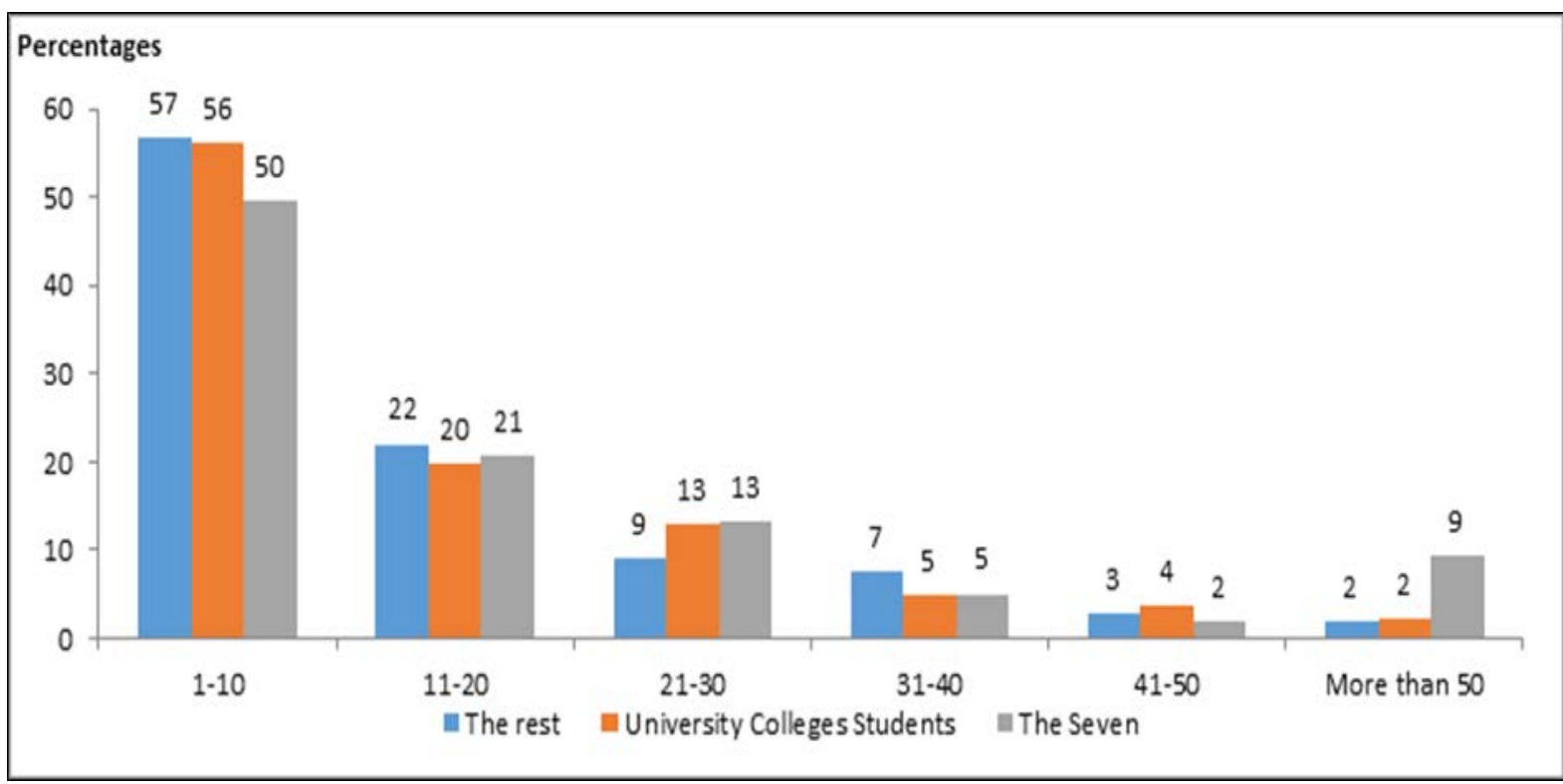

Figure 4: Number of clicks per login, grouped into intervals and adjusted for group size.

Figure 4 gives an overview of the three groups on which we have chosen to focus. The bars represent those who received a diploma (grey) (the seven), the group of UC students who did not (orange) and the rest of the participants (blue). Each of the six groupings of bars (blue, orange and grey) divides the participants' visits into intervals. Visits during which the participant only clicked on (the same or different) resource(s) between one and 10 times are grouped in the first interval from the left. The last interval on the right shows visits during which the participant clicked on resources more than 50 times. From this we can see that the overwhelming majority of visits involved very little activity (1-10 clicks).

From figure 3 we already know that group 2 (the seven) had focused work sessions-i.e. they logged on few times with a high level of activity (more clicks) during each session. From figure 3, we can also see that group 2 (the seven) accessed multiple learning resources and activities when they were logged in (the many vertical rows of the same colour).

The following figures 5, 6, 7 and 8 below are to be read in the same way as figure 3, the only differences being that the figures display information for just one participant, thus eliminating the need for colour coding. Furthermore, the lower amount of information makes it possible to display log-in activity at a higher granularity (i.e. shorter intervals).

While the intended design assumed a course module to be moderated and to last for two weeks with a normal weekly workload, group 2 (the seven) did not conform to this expected behaviour. Their activity pattern during the course involved logging in a small number of times per module and being very active during each log in. For all participants in group 2, there was a pattern of working for bursts of time lasting two to five hours and then waiting for the next module to open. Below in figure 5, we can see the activity patterns of the most active of the seven participants from group 2 (Student 3261). This person earned 10 badges with a total of 697 clicks, equal to 70 clicks per badge. 


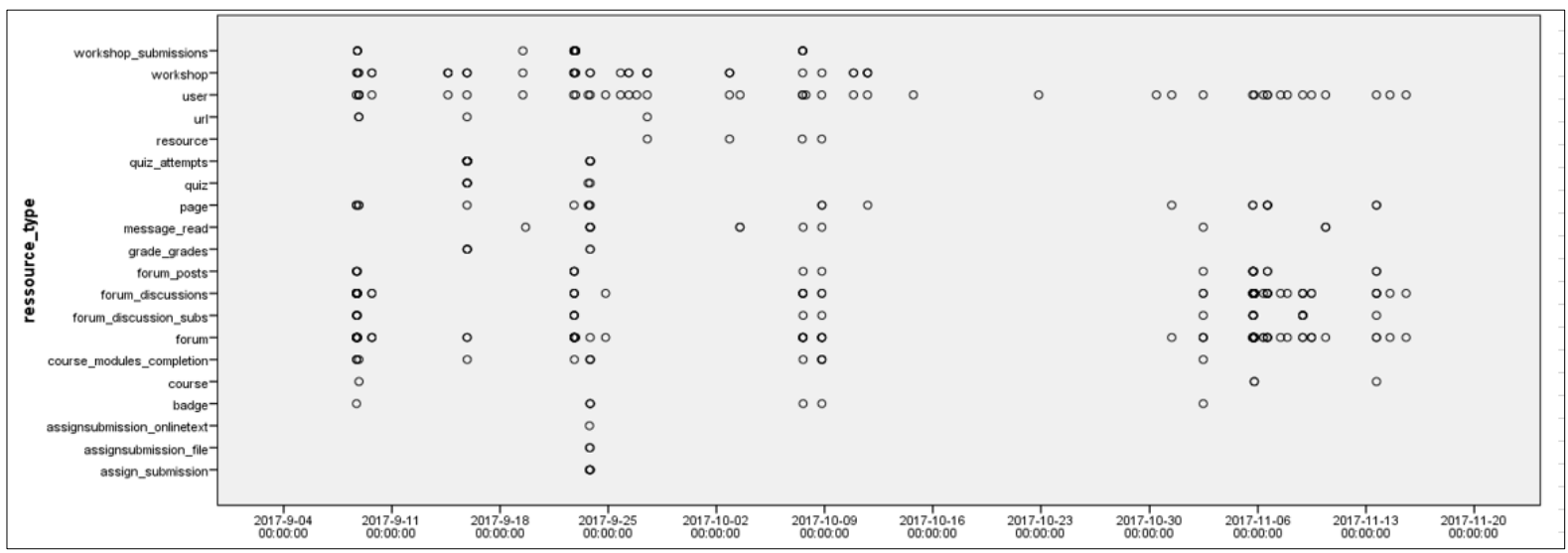

Figure 5: The activity pattern for student 3261 over the length of the course.

The activity pattern for student 3261 (figure 5) was also seen in the least active member of group 2 student 3643 (figure 6), that earned 7 badges with 268 clicks, equal to 38 clicks per badge.

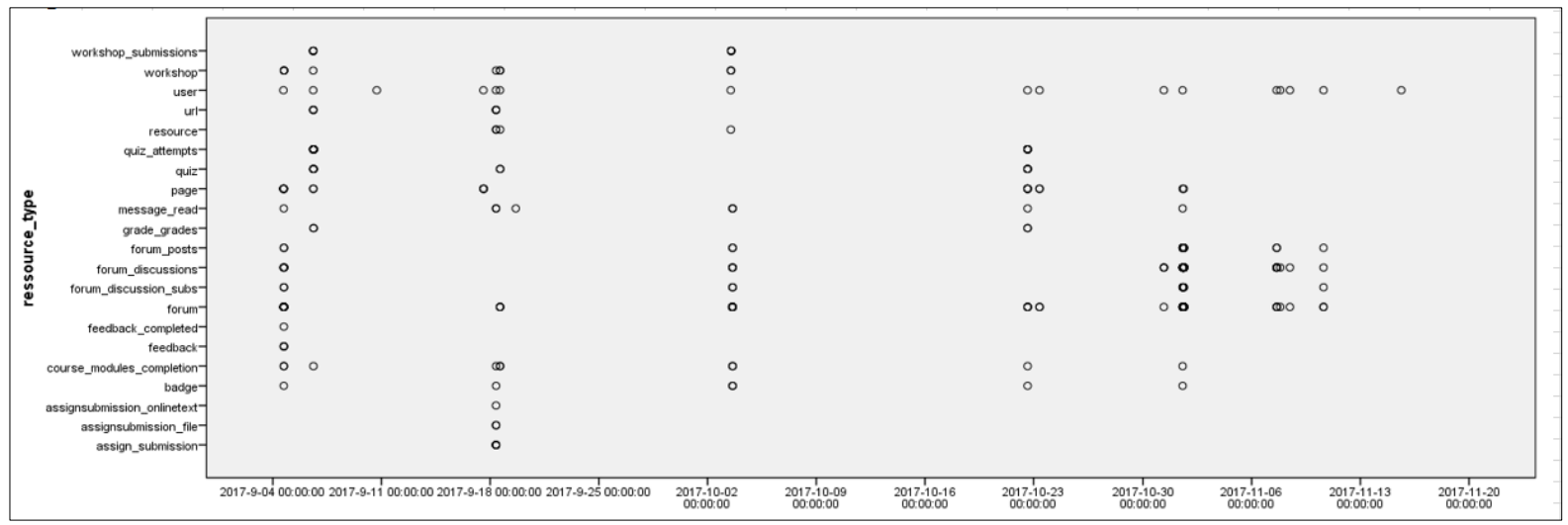

Figure 6: The activity pattern for student 3643 over the length of the course.

Looking closer at a single day of two students, the same activity pattern emerges more clearly.

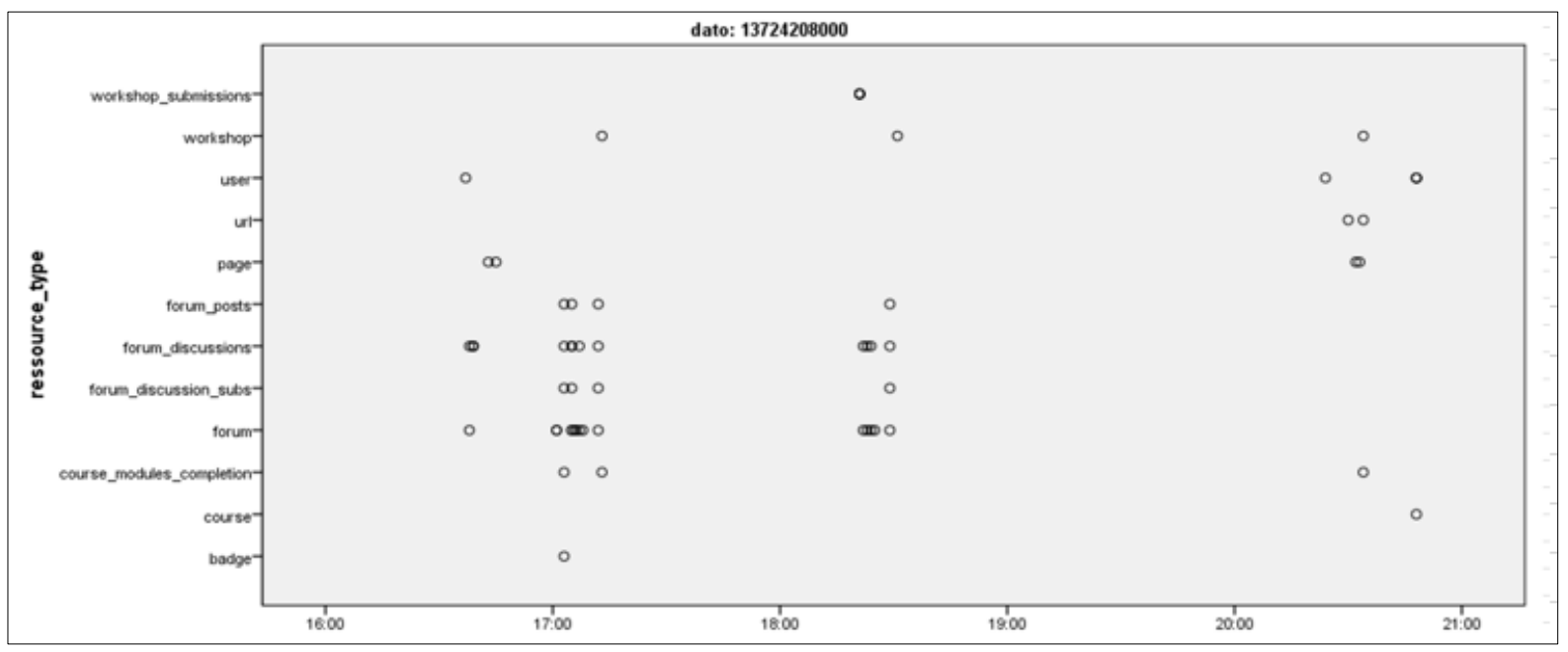

Figure 7: The activity pattern for student 3261 in a single day. 
The above figure shows how student 3261 completed the entire module in five intensive hours in a single day, during which the module's resources and activities were accessed and completed.

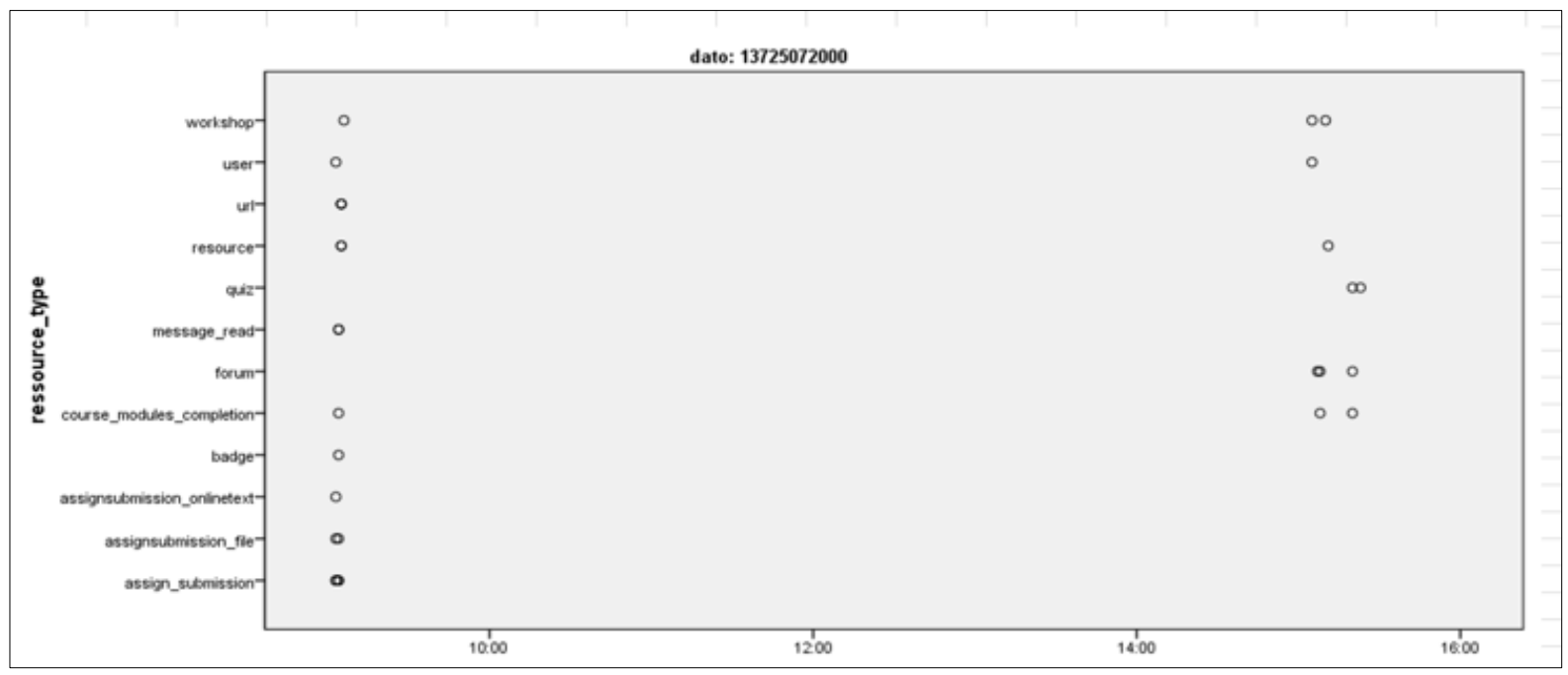

Figure 8: The activity pattern for student 3643 during a single day.

The above figure shows how student 3643, in a single day (with a short break), completed a specialization module (2a-c) using 29 clicks (in addition to four clicks the day prior).

\section{Constraints that enable study efficiency}

Even though it is highly likely that the designers did not intend users to be able to complete the MOOC in very efficient bursts of activity, it is interesting to examine the characteristics that made such behaviour possible - not least because such a design, in a sense, embodies an implicit critique of the way we traditionally design education and, therefore, represents a potential break with tradition and an alternative way of creating learning environments. With this in mind, we have analyzed the intended design of the modules and sequences in the MOOC. Our analysis has been compiled into Figure 9 below, which shows three different design principles that take different types of technical and social constraints into consideration. It shows the limits or borders of activity. The innermost circle signifies activities that are completely contained in the Moodle environment. There is no need to exit Moodle in order to engage in such activities. The middle circle signifies activities that may require exiting Moodle-for instance, to write text in Word-but are still confined to the computer. The outermost circle signifies activities that require work to be done outside the computer environment-for instance, engaging in work in a school. 


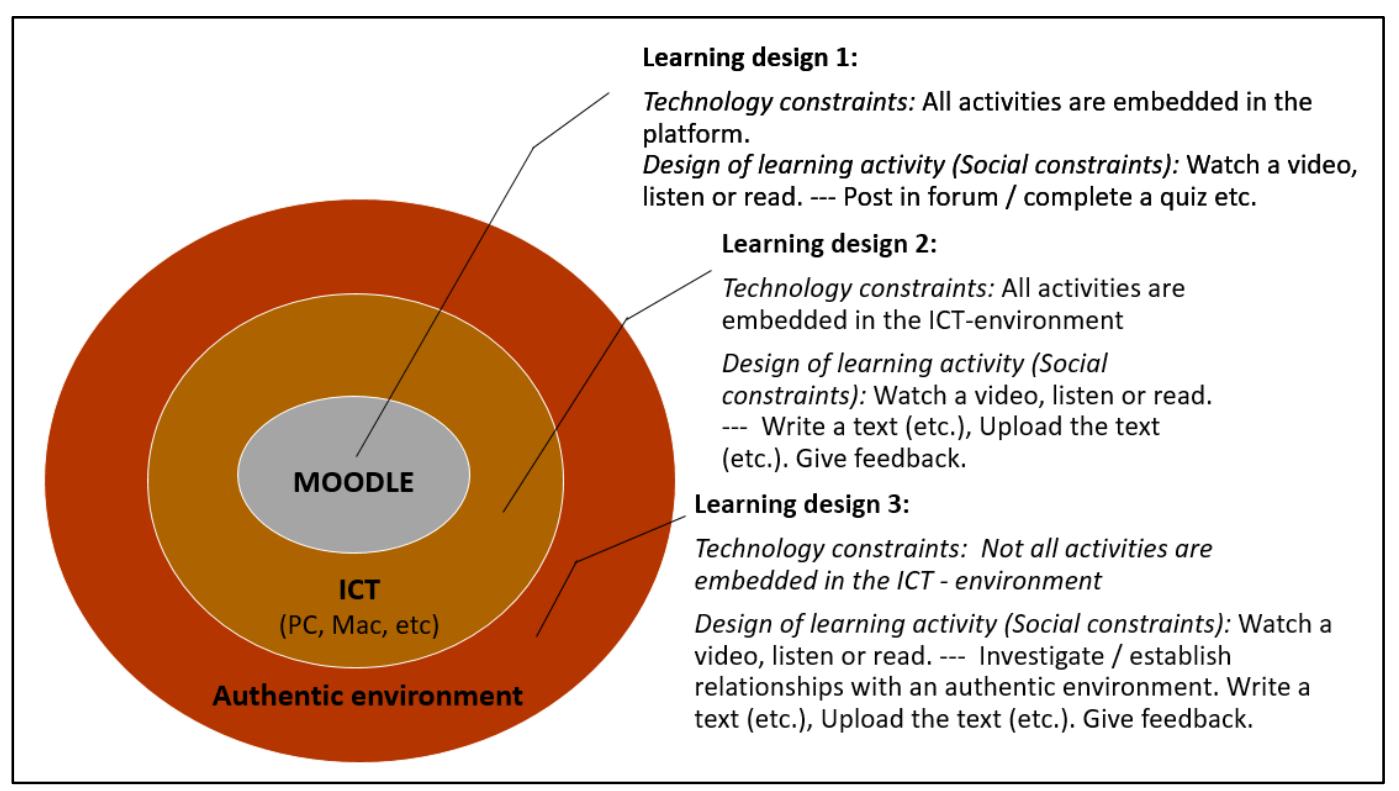

Figure 9: Learning design principles—constraints and study efficiency.

Our analysis of the intended design shows that modules $1,2 \mathrm{a} / \mathrm{b} / \mathrm{c}$ and 3 were primarily designed within the borders of learning designs 1 and 2 . Students can access all necessary resources in the platform and complete activities (e.g. forum discussions and quizzes) directly in Moodle or with other ICT-tools on their computer. Simply put, the design constraints on these modules generate a learning space in which students can be active without leaving their desks. In module 4 , this is not possible. Here, participants were expected to establish real contact with an external partner and cooperate on an actual task. This constitutes a social constraint built into the module that creates a significant threshold for completion. In terms of study efficiency, such a constraint makes it infeasible to work in short, concentrated bursts of activity. However, the module also offers the possibility of simulating cooperation in an authentic context. Five of the seven participants from group 2 used this option and thereby completed module 4 using the exact same approach as before - allowing them to continue to work in bursts of activity.

\section{Module design and study activity patterns - comparing the three cohorts}

If we take a closer look at the activities across modules, we can see the activities of all participants collectively. 


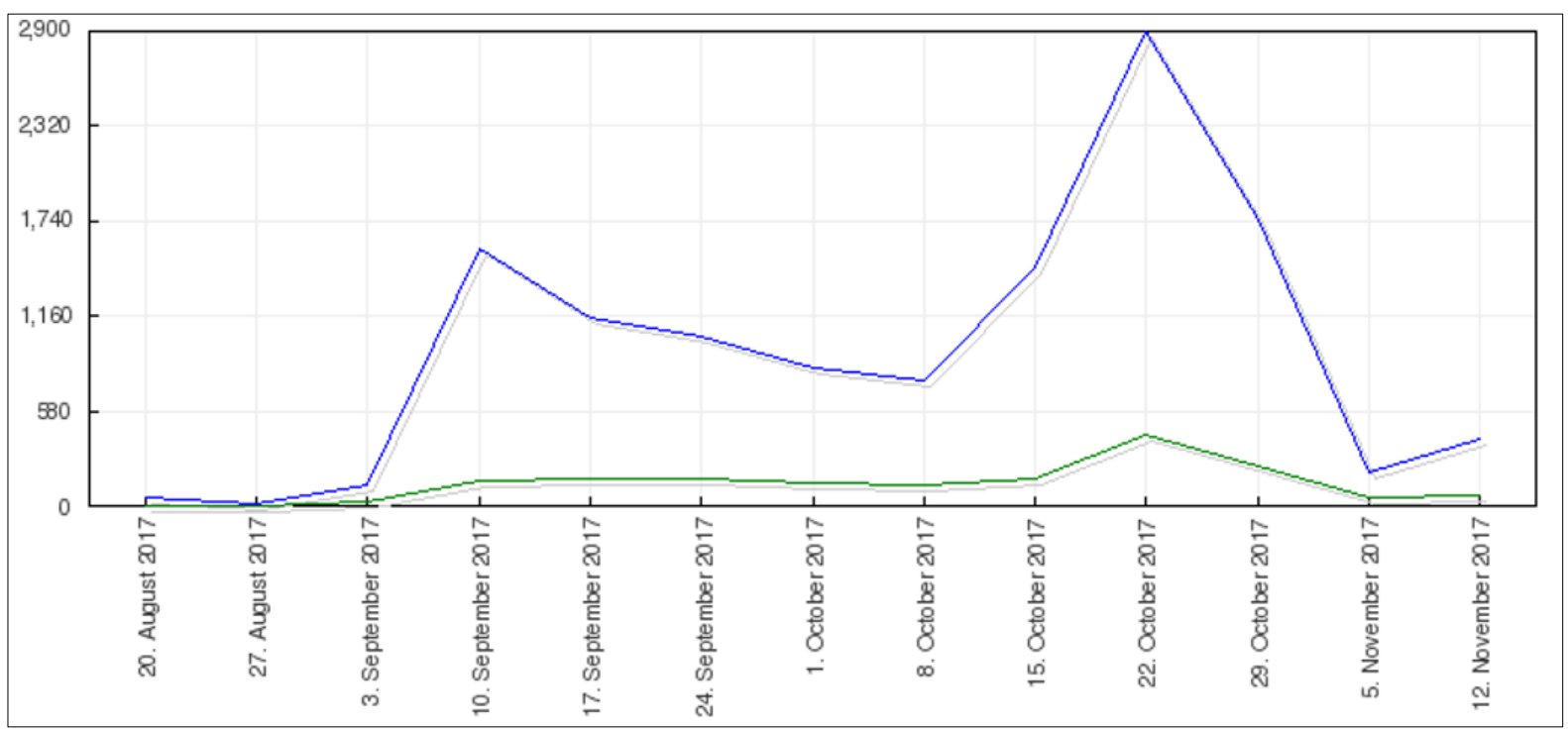

Figure 10: Weekly activity: all participants, all modules.

Time intervals are on thex-axis, while they-axis shows activity. Blue signifies the number of pageviews. Green signifies the number of posts in the forums. The figure shows a very different activity pattern than has been found generally in MOOC research. Normally, participants are very active at the beginning of the course, after which participation drops. The reason that both pageviews and posts increased over time is revealed when we divide the activity by the three cohorts $(0,1$ and 2$)$.

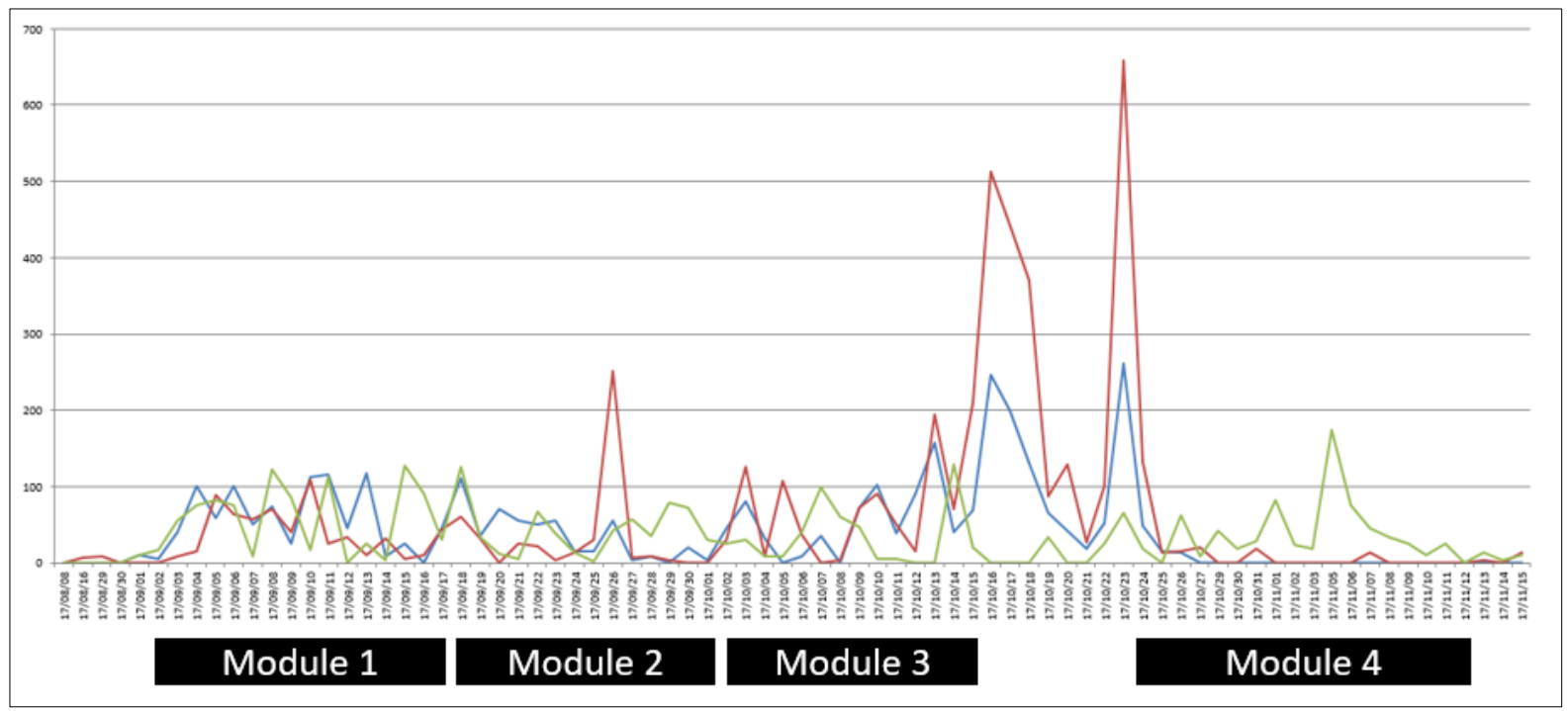

Figure 11: Number of clicks per day for the three cohorts. Green (the seven [' 2 ']), red (the UC students [' 1 ']), and blue (the rest ['0']).

Figure 11 shows activity over time in the same way as Figure 10 but divided into the three groups and colour-coded. The figure shows a pattern. Only group 2 (the seven) was active during all the modules (green). Group 1 was active while the MOOC was a part of their course (large red spikes), particularly in the week of 14-24 October (the Danish fall vacation period). Almost no one in group 0 and only some in group 1 were active during module 4 , the final module (on the right-hand side). Module 4 generated 31 badges. Group 2 accounted for 11 (35\% or 1.5 each) while group 1 accounted for 20 ( $64 \%$ or 0.27 each). The same pattern can be seen in the following images (figures 12, 13 and 14). Each image gives insight into a different type of activity (clicking on resources [figure 12], posting in forums [figure 13] and 
reading posts [figure 14]). Only group 2 participants (the seven) (yellow rings) were active during all modules. The UC students (green rings) were very active during select periods, while all activity of the remaining participants (blue rings) grinds to a halt when we reach the last module.

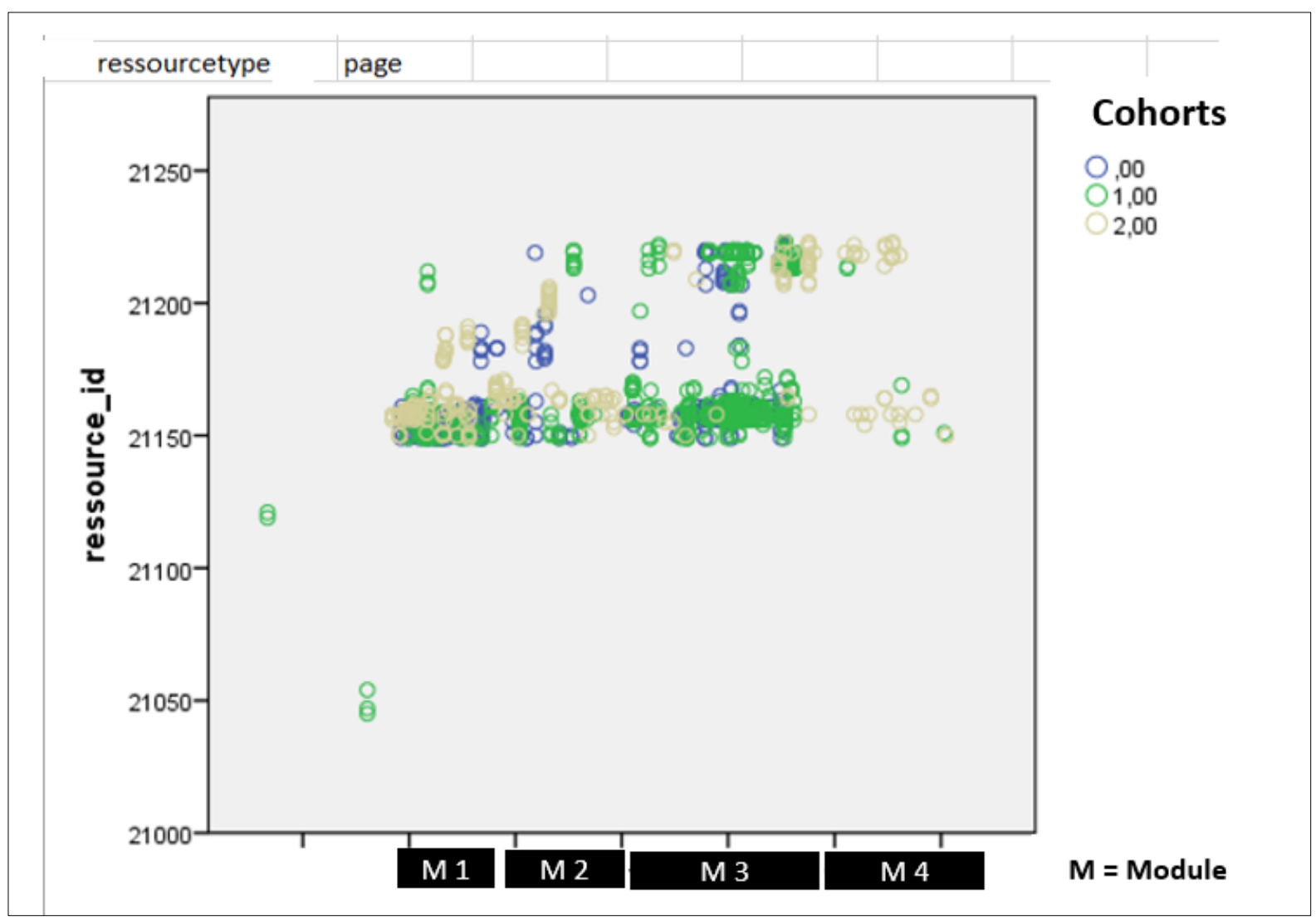

Figure 12: The three cohorts' access to unique pages in the MOOC divided into module periods. 


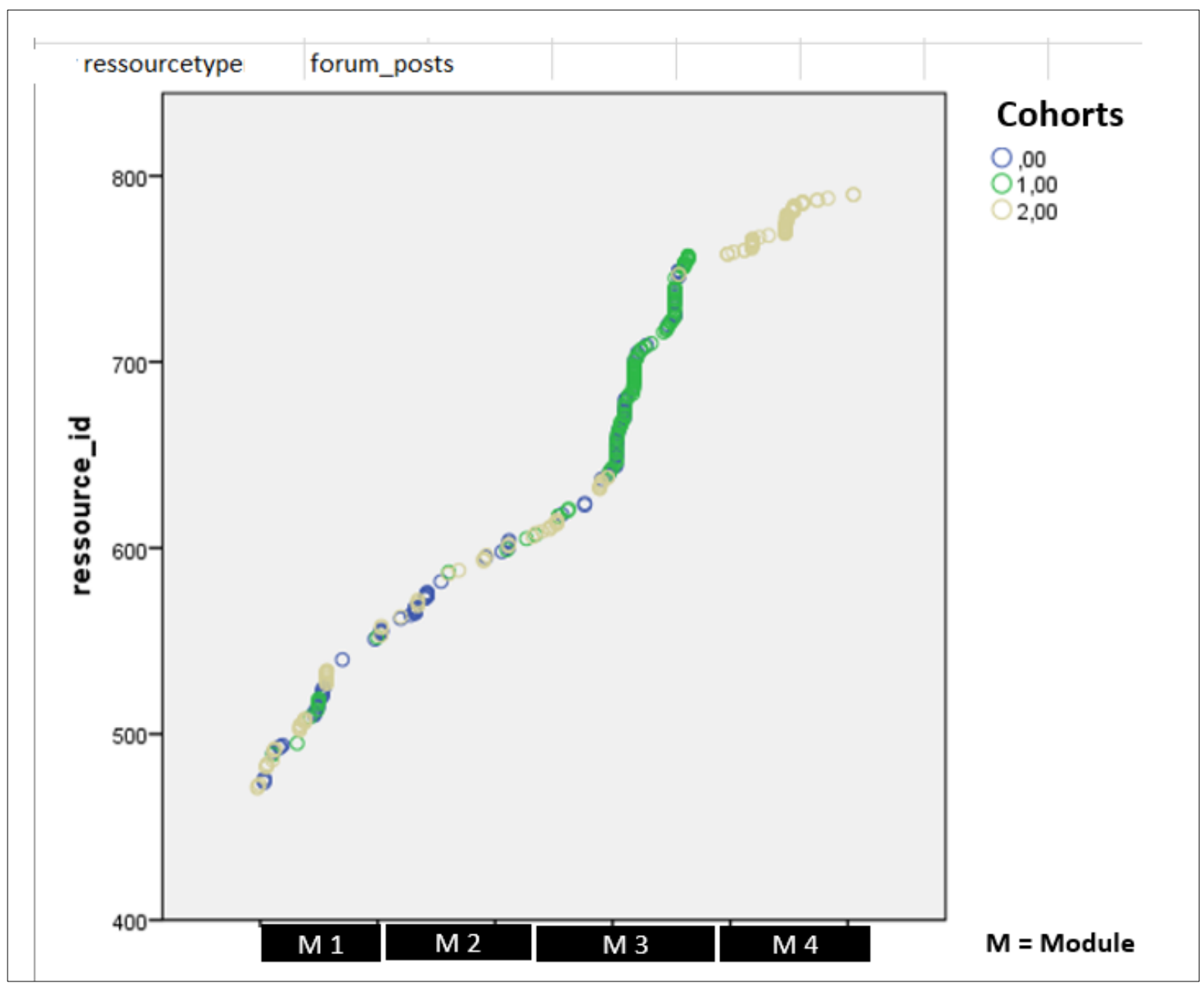

Figure 13: Postings in forums during module periods for the three cohorts. 


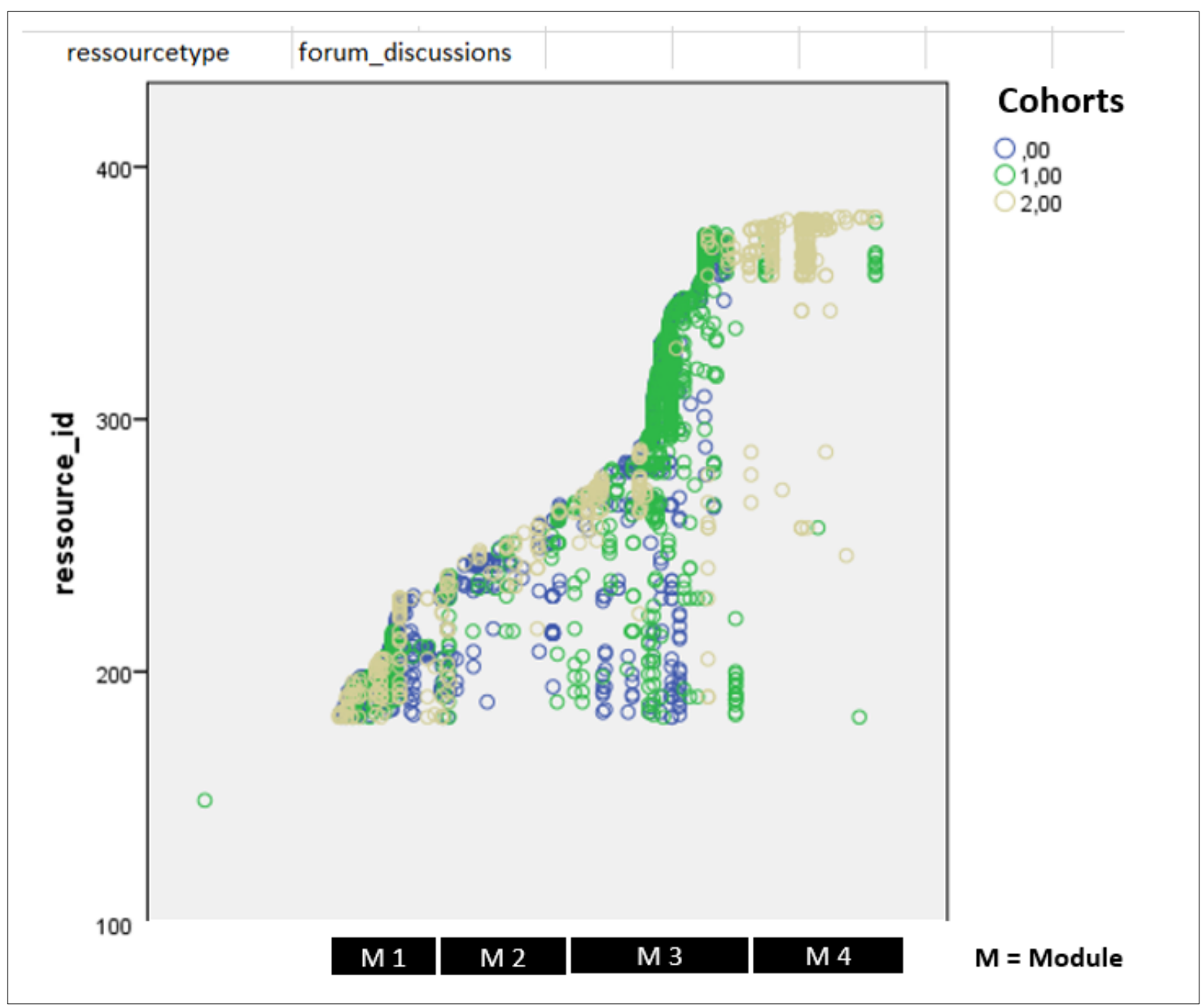

Figure 14: Reading of posts during module periods for the three cohorts.

We chose to call figure 14 'the dinosaur that lost its head.' The figure synthesizes our findings regarding activity over the three cohorts. Group 1 was active during a specific period, when the MOOC was part of their regular course. This confirms research showing that MOOCs intended for other audiences can be used in formal settings (Kovanović, Gašević, Joksimović, Siemens \& Hatala, 2015). Group 2 (the seven) was active throughout the course period, while group 0 was active until module 4 , at which point it dropped out completely. The dinosaur, signifying the MOOC design, lost its head. A simplistic explanation of this would ascribe it to the week of vacation that interrupted the flow of work; however, we believe this to be unlikely: A different interpretation, as argued above, is that module 4 is designed with different constraints on study behaviour. This module does not provide the same opportunities for study efficiency as the other modules because it requires reaching out and establishing an external relationship. Group 2 stood out because they seemed to find a solution to this, while the majority of participants simply saw an insurmountable threshold and abandoned the MOOC. However, there might be additional information that sheds light on why the dinosaur lost its head.

\section{Module design and pedagogical approaches}

If we look at the pedagogical approach behind the intended learning design (ld), stark differences becomeapparent: The differences revolve around the choice of content categories within the MOOC and the learning theory used. Modules 1, $2 \mathrm{a} / \mathrm{b} / \mathrm{c}$ and 3 aim to establish knowledge of 'the open school' and the understanding of concepts and theories in relation to it, as well as applying this knowledge to cases. 
Overall, the ld embodies learning goals that prioritize the lower and middle parts of Bloom's taxonomy (remember, understand, apply, analyse, evaluate, create) (Bloom, 1956). The pedagogical approach is to focus on knowledge acquisition (videos and texts), checking for understanding (quizzes) and engaging in dialogue (forum discussions, peer-to-peer review). Using Diana Laurillard's (2012) concept, we can say that the ld utilises 'Learning through Acquisition', 'Learning through Discussion' and 'Learning through Collaboration'.

The last module sets itself apart by being a 'project module'. The designers presented the module as follows (translated from Danish):

This module is intended to support collaboration with other MOOC participants, as well as the completion of a project in practice. We recommend that you try to establish a network or cooperate with others from the beginning of the course, and that you are active throughout this process'.

The task of creating a practice project is described in the following manner (translated from danish): You should, by using your network, plan and, if possible, execute an open school practice project'.

Thus, module 4 works at the top level of Bloom's taxonomy: create. Participants are supported through the introduction of helpful tools whereby learning goals further down the taxonomy are included in the work, but the goal remains the creative production of a practice project between a school and its environment. The primary pedagogical approach here is what Laurillard (2012) refers to as learning through practice', which counts as a heading for 'authentic', 'situated' and 'experiential' learning.

The most important insight taken from the above is that the intended design shifted the constraints of module 4 and prompted a complete rejection of processes that either require a change of effort as a situated and experiential learning approach and/ or operate at a higher cognitive level. It is interesting to note that module 4 could fairly easily have been aligned with the other modules by students simulating a practice project, i.e. by describing a simulated collaboration with an imagined partner. The designers mention this option in a single sentence (translated from danish): We emphasize that it is not a requirement that you work with others to participate in the MOOC and create a practice project-it is possible for you to work alone'.

\section{Conclusions and further research}

Our work here is important in the sense that we show that working with learning analytics can contribute valuable knowledge to intended designs and thereby create fruitful discussions regarding educational designers and their learning designs. Our analyses show that there is often a huge difference between the intended design and the design as implemented.

Each course module was designed for a normal 37-hour weekly workload. However, the seven participants who completed the course with a diploma used far fewer study hours. Even though it was not intended, the course designers made it possible to be study efficient in three out of four modules. These modules were designed so that the students could complete all assignments without leaving their desk and comprised activities based on pedagogical approaches like 'Learning through Acquisition', 'Learning through Discussion' and 'Learning through Collaboration' and with learning goals that relate to the lower and middle parts of Bloom's taxonomy. The last module was designed with completely different constraints in terms of study efficiency: The learning goals relate to the top level of Bloom's taxonomy, and the activities were based on a different pedagogical approach: 'Learning through Practice'. Because of these changes, the 'dinosaur lost its head' in terms of student dropouts. Of course, a group of seven participants does not establish a basis for generalization but that is not our point anyway. We want to show that there can be a difference between a didactical designer's intentions for a design (students working 37 hours a week) and the actual effort put in by students. A learning analytics 
approach is necessary for these insights to become transparent for the designers - providing them with important knowledge that can be used to inform future designs.

This raises a number of questions that should be considered by MOOC learning designers, such as the following: Is the MOOC format most suitable for the lower and middle parts of Bloom's taxonomy? When constructing a MOOC, should the learning design' be chosen based only on pedagogical assumptions like 'Learning through Acquisition', 'Learning through Discussion' and 'Learning through Collaboration'? If not, how can knowledge forms of a higher order such as situated and experiential learning be incorporated into a MOOC design? Can problem-based learning, e.g., play a role, or is it necessary to focus on a more 'simulated' learning approach in the intended design?

Educational designers create intended learning designs that they believe will be implemented in certain ways. However, our analyses show there is often a huge difference between the intended design and the design as implemented. This is one of the main arguments for educational designers to integrate learning analytics into their everyday practice. As a result of doing so, they will a) become better learning designers and b) move teachers, as professionals, toward becoming professional educational designers (as Laurillard (2012) puts it, teaching is a design science.) Then they can develop learning designs that exhibit a closer connection between the intended and implemented design. This we will refer to as an empowerment approach; through it, professional learning designers can create more robust learning designs, using a variety of data to support learning design decision-making.

\section{References}

Akker, J.V.D., Gravemeijer, K., McKenney, S. \& Nieveen, N. (2006). Educational design research. New York: Routledge.

Bakharia, A., Corrin, L., de Barba, P., Kennedy, G., Gašević, D., Mulder, R. \& Lockyer, L. (2016). A conceptual framework linking learning design with learning analytics. Proceedings of the Sixth International Conference on Learning Analytics \& Knowledge (pp. 329- 338). New York: ACM.

Bayne, S. \& Ross, J . (2014). The pedagogy of the Massive Open Online Course: The UK view. Edinburgh: The Higher Education Academy.

Bloom, B.S., (Ed.) (1956). Taxonomy of educational objectives: The classification of educational goals: Handbook I, cognitive domain. New York: Longman.

Brophy, J . (1995). Thoughts on the qualitative-quantitative debate. Paper presented at the Annual Meeting of the National Council for the Social Studies, Chicago, USA.

Chatti, M.A., Dyckhoff, A.L., Schroeder, U. \& Thüs, H. (2012). A reference model for learning analytics. International J ournal of Technology Enhanced Learning, 4(5), pp. 318- 331.

Class-Central (2016). By the numbers: MOOCs in 2016. Retrieved from https:// www.classcentral.com/ report/ mooc-stats-2016/

Clow, D. (2012). The learning analytics cycle: Closing the loop effectively. Proceedings of the Second International Conference on Learning Analytics and Knowledge (pp. 134- 137). Vancouver, Canada

Conole, G. (2013). Designing for learning in an open world. New York: Springer.

Dalziel, J ., Conole, G., Wills, S., Walker, S., Bennett, S., Dobozy, E, Cameron, L., Badilescu-Buga, E. \& Bower, M. (2016). The Larnaca Declaration on learning design. J ournal of Interactive Media in Education, 1(7), 1- 24.

Dyckhoff, A.L., Zielke, D., Bültmann, M., Chatti, M.A. \& Schroeder, U. (2012). Design and implementation of a learning analytics toolkit for teachers. Educational Technology \& Society, 15(3), 58- 76. 
Flyvbjerg, B. (2006). Five misunderstandings about case-study research. Qualitative Inquiry, 12(2), $219-245$.

Gašević, D., Dawson, S. \& Pardo, A. (2016). How do we start? State and directions of learning analytics adoption. Oslo, Norway: International Council for Open and Distance Education.

Gynther, K. (2016). Design Framework for an Adaptive MOOC Enhanced by Blended Learning: Supplementary Training and Personalized Learning for Teacher Professional Development. Electronic J ournal of eLearning, 14(1), 15-30. Retrieved from: www.ejel.org

Gynther, K., Christensen, O. \&J ørnø, R. (2013) . Synkrone online læringsmiljøer - didaktisk design for synkron undervisning understøttet af digitale teknologier. Læring og Medier, 11. Retrieved from: https:// tidsskrift.dk/ lom/ article/ view/ 8660/ 13399

Hestbech, A. M. \&Nortvig, A.-M. (Red). (2016). Nye design for undervisning og uddannelse: MOOCs - Massive Open Online Courses. Frederikshavn: Dafolo.

Hung, D., Lim, K. \& Huang, D. (2010). Extending and scaling technology-based innovations through research. In Inspired by Technology, Driven by Pedagogy-A systemic approach to technology-based school innovations, Educational Research and Innovation, Paris: OECD Publishing.

J ørnø, R. \& Gynther, K. (2018). What constitutes an 'actionable insight' in learning analytics? J ournal of Learning Analytics, 5(3), 198-221.

Kellogg, S., Booth, S. \& Oliver, K. (2014). A social network perspective on peer supported learning in MOOCs for educators. The International Review of Research in Open and Distance Learning, 15(5).

Kovanović, V., Gašević, D., Joksimović, S., Siemens, G. \& Hatala, M. (2015). MOOCs in the news: A European perspective. Proceedings of WOW! Europe Embraces MOOCs (pp. 1- 20). Rome: EADTU.

LAK (2011). Call for Papers of the 1st International Conference on Learning Analytics \& Knowledge. Tilgået 12 april 2019 via https:// tekri.athabascau.ca/ analytics/ .

Laso, J . A., Peco, P.P. \& Lujan-Mora. S. (2013). Using Open Badges as certification in a MOOC. Proceedings of the 6th International Conference of Education, Research and Innovation (ICERI 2013), pp. 1809-1818.

Laurillard, D. (2012). Teaching as a design Science - Building Pedagogical Patterns for Learning and Technology. London: Routledge.

Leo, D.H., Rodriguez-Triana, M., Inventado, P.S. \&Mor, Y. (2017). Preface. In Special Issue on: Connecting Learning Design and Learning Analytics. Interaction Design \&Architecture(s), 33, 3- 8.

Liu, D.Y., Bartimote-Aufflick, K., Pardo, A. \& Bridgeman, A.J . (2017). Data-driven personalization of student learning support in higher education. In A. Peña-Ayala (ed.). Learning analytics: Fundaments, applications, and trends-A view of the current state of the art to enhance e-learning (pp. 143-170). Cham, Switzerland: Springer.

Lockyer, L., Heathcote, E. \&Dawson, S. (2013). Informing pedagogical action: Aligning learning analytics with learning design. American Behavioral Scientist, 57(10), 1439- 1459.

McKenney, S. \& Reeves, T.C. (2012). Conducting educational design research. London \&New York: Routledge.

Nguyen, Q., Rienties, B. \&Toetenel, L. (2017). Unravelling the dynamics of instructional practice: A longitudinal study on learning design and VLE activities. ACM International Conference Proceeding Series (pp. 168- 177). New York, NY: ACM. 
Nortvig, A.-M. (2016). Learning analytics som udgangspunkt for refleksion over didaktisk design i blended learning, Læring og Medier, 16. Retrieved from: https:// tidsskrift.dk/lom/ article/ view/ 24150/21700

Onah, D.F.P., Sinclair, J . \& Boyatt, R. (2014). Dropout rates of massive open online courses: Behavioural patterns. Proceedings of the Sixth International Conference on Education and New Learning Technologies (EDULEARN14) (pp. 5825-5834). Barcelona, Spain.

Persico, D. \& Pozzi, F. (2015). Informing learning design with learning analytics to improve teacher inquiry. British J ournal of Educational Technology, 46(2), 230- 248.

Reeves, T.C. (2000). Socially responsible educational technology research. Educational Technology, 40(6), $19-28$.

Rienties, B., Nguyen, Q., Holmes, W. \& Reedy, K. (2017). A review of ten years of implementation and research in aligning learning design with learning analytics at the Open University UK. In Special Issue on: Connecting Learning Design and Learning Analytics. Interaction Design \&Architecture(s), 33, 134- 154.

Ross, S.M. (1990). Writing in a computer-saturated classroom. Paper presented at the Annual Meeting of the College Reading Association, Nashville, USA.

Sclater, N., Peasgood, A. \& Mullan, J . (2016). Learning analytics in higher education: A review of UK and international practice. Bristol: J ISC. Retrieved from https:// www.jisc.ac.uk/ sites/ default/files/ learninganalytics-in-he-v2_0.pdf

Sergis, S. \& Sampson, D.G. (2017). Teaching and learning analytics to support teacher inquiry: A systematic literature review. In A. Peña-Ayala (ed.). Learning analytics: Fundaments, applications, and trends-View of the current state of the art to enhance elearning (pp. 25- 63). Cham, Switzerland: Springer.

Vivian, R., Falkner, K. \& Falkner, N. (2014). Addressing the challenges of a new digital technologies curriculum: MOOCs as a scalable solution for teacher professional development. Research in Learning Technology, 22.

Wise, A.F., Vytasek, J .M., Hausknecht, S.N. \&Zhao, Y. (2016). Developing learning analytics design knowledge in the "middle space": The student tuning model and align design framework for learning analytics use. Online Learning, 20(2), 1- 28. 


\section{Forfattere}

\section{René Boyer Christiansen}

Docent, Ph.d.

Center for Skole og Læring, PH Absalon

Tilnyttet forskningsprogrammet Digitale Læringsmiljøer og Didaktisk Design. Besøg faglig profil her.

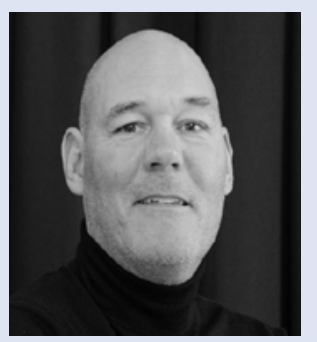

\section{Karsten Gynther}

Docent, Forskningsprogramleder

Center for Skole og Læring, PH Absalon

Leder af forskningsprogrammet Digitale Læringsmiljøer og Didaktisk

Design. Besøg faglig profil her.

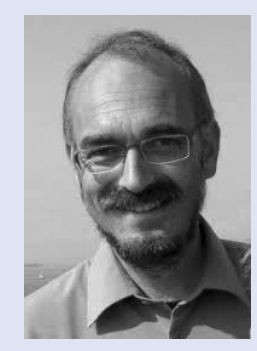

\section{Rasmus J ørnø}

Lektor, Ph.d.

Center for Skole og Læring, PH Absalon

Tilnyttet forskningsprogrammet Digitale Læringsmiljøer og Didaktisk Design. Besøg faglig profil her.

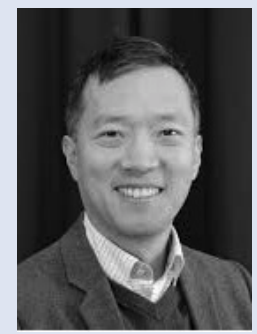

